\title{
Evidence from spatial pattern analysis for the anatomical spread of $\alpha$-synuclein pathology in Parkinson's disease dementia
}

\author{
Richard A. Armstrong \\ Vision Sciences, Aston University, Birmingham, United Kingdom
}

\begin{abstract}
The objective of this study was to determine whether there is evidence from quantitative morphometry and spatial pattern analysis to support the hypothesis of anatomical spread of $\alpha$-synuclein in Parkinson's disease dementia $(P D D)$. Hence, clustering of $\alpha$-synuclein-immunoreactive Lewy bodies (LB), Lewy neurites (LN), and Lewy grains (LG) was studied in $\alpha$-synuclein-immunolabeled sections of cortical and limbic regions in 12 cases of PDD. The data suggested that: (1) $L B, L N$, and $L G$ occurred in clusters which in $63 \%$ of regions were regularly distributed parallel to the tissue boundary, (2) in approximately $30 \%$ of cortical regions, the estimated cluster size of $L B, L N$, and $L G$ was within the size range of cellular columns associated with the cortico-cortical pathways, (3) regularly distributed clusters were present in anatomically connected regions, and (4) the clustering pattern was similar to that of prion protein (PrPsc) deposits in Creutzfeldt-Jacob disease (CJD). The clustering patterns of $L B, L N$, and $L G$ were similar to those exhibited by cellular inclusions in other synucleinopathies and by PrPsc deposits in prion disease and therefore, anatomical spread of pathogenic $\alpha$-synuclein could be involved in the pathogenesis of PDD.
\end{abstract}

Key words: Parkinson disease dementia (PDD), synucleinopathy, Lewy body (LB), Lewy neurite (LN), Lewy grain (LG), spatial pattern, anatomical spread.

\section{Introduction}

The 'synucleinopathies', viz. Parkinson's disease dementia (PDD), dementia with Lewy bodies (DLB), and multiple system atrophy (MSA) are characterized by the formation of cellular inclusions containing pathological forms of the pre-synaptic protein $\alpha$-synuclein. These pathologies include Lewy bodies $(\mathrm{LB})$, Lewy neurites (LN), and Lewy grains (LG) in PDD and DLB [33] and glial cytoplasmic inclusions (GCI) in MSA [31]. $\alpha$-Synuclein is a small molecular weight protein which regulates the functioning of dopamine transporter and tyrosine hydroxylase [27]. In normal brain, monomers of $\alpha$-synuclein are unfolded soluble proteins, the oligomeric and fibrillar species existing in equilibrium. In the synucleinopathies, however, aggregation of $\alpha$-synuclein occurs to form $\beta$-sheet configurations rich in amyloid [34] resulting in the formation of pathogenic inclusions such as LB.

Pathogenic $\alpha$-synuclein may be secreted from cells, enter other cells, and seed small intracellular aggregates to form larger inclusions $[23,35,37]$. Hence, in PDD, pathological $\alpha$-synuclein may exhibit 'prion-like' behaviour and propagate through the brain via anatomical connections. In the prion dis- 
ease, Creutzfeldt-Jakob disease (CJD), in which propagation of prion protein $\left(\mathrm{PrP}^{\mathrm{sc}}\right)$ along anatomical pathways is well established [12,13], PrPsc deposits are clustered in the cerebral cortex, the clusters often being regularly distributed parallel to the pia mater $[7,9]$. Clustering could therefore be a consequence of PrPsc spreading among regions via anatomical pathways [7]. To determine whether similar clustering of $\alpha$-synuclein pathology occurs in PDD, the spatial patterns of $L B, L N$, and $L G$ were studied in cortical and limbic regions in twelve cases of PDD.

\section{Material and methods}

\section{Cases}

Parkinson's disease dementia cases $(n=12$, details in Table I) were consecutive cases meeting the diagnostic criteria for Parkinson's disease (PD) and PDD and were obtained from the Movement Disorders Center at Washington University School of Medicine in St. Louis $[11,26]$. Initial diagnosis of PD was based on modified United Kingdom Parkinson Disease Society Brain Bank (UKPDSBB) clinical diagnostic criteria [24]: (1) bradykinesia was present in association with at least one of the following, viz. rigidity, 4-6 $\mathrm{Hz}$ rest tremor, or postural instability, (2) three supporting criteria were also present such as unilateral onset, rest tremor, a progressive disorder, persistent asymmetry, a clinical condition present for more than 10 years, or excellent response to levodopa, and (3) the various exclusion criteria were applied such as the absence of stroke, persistent head injury, definite encephalitis, oculogyric crisis, family history of the disease, sustained remission, unilateral features after three years, progressive supranuclear palsy (PSP), early severe autonomic involvement, early signs of dementia, Babinski sign, cerebral tumor, exposure to MPTP, and negative response to levodopa [24]. Age of PD onset was determined by chart review and defined by onset of motor symptoms. Dementia in PD was determined by clinical assessment including the presence of impairment of attention, memory, executive, and visuo-spatial function together with behavioural disturbance, hallucinations and apathy [20]. The main pathological correlate of PDD is the presence of Lewy-body type degeneration in the cerebral cortex and limbic regions [20]. In addition, PDD cases are frequently associated with Alzheimer's disease neuropathologic change (ADNC) and the degree of ADNC was assessed using National Institute on Aging-Alzheimer's (NIA-AA) association guidelines 'ABC' [25]. This system uses four-point scales to assess the abundance of $\beta$-amyloid ( $A \beta$ ) deposits

Table I. Demographic features, duration of disease, and disease stage of the twelve cases of Parkinson disease dementia (PDD). Lewy body (LB) stage was assessed using a PD staging scale (range: 0, 1-6) and the McKeith et al. staging scale (McKeith et al. 1996, 2005). Alzheimer's disease neuropathological change (ADNC) was rated using the National Institute on Aging-Alzheimer's (NIA-AA) association guidelines: A stage indicating $\beta$-amyloid $(A \beta)$ deposition, $B$ stage frequency of tau-immunoreactive neurofibrillary tangles (NFT), and C stage frequency of neuritic plaques (NP)

\begin{tabular}{|c|c|c|c|c|c|c|c|c|c|}
\hline \multirow[t]{2}{*}{ Case } & \multirow[t]{2}{*}{ Sex } & \multirow[t]{2}{*}{ Age } & \multirow{2}{*}{$\begin{array}{l}\text { Dur. } \\
\text { (PD) }\end{array}$} & \multirow{2}{*}{$\begin{array}{l}\text { Dur. } \\
\text { (DM) }\end{array}$} & \multirow{2}{*}{$\begin{array}{c}\text { LB } \\
\text { stage }\end{array}$} & \multicolumn{3}{|c|}{ ADNC } & \multirow[t]{2}{*}{ Level of $A D$} \\
\hline & & & & & & A & B & C & \\
\hline A & $\mathrm{F}$ & 82 & 12 & 9 & 6 & 0 & 2 & 0 & $N$ \\
\hline B & M & 80 & 18 & 7 & 6 & 3 & 2 & 1 & I \\
\hline C & $M$ & 78 & 12 & 1 & 6 & 1 & 3 & 0 & $\mathrm{~L}$ \\
\hline $\mathrm{D}$ & $M$ & 79 & 19 & 6 & 6 & 1 & 1 & 0 & $\mathrm{~L}$ \\
\hline$E$ & $M$ & 71 & 8 & 7 & 6 & 3 & 2 & 1 & 1 \\
\hline $\mathrm{F}$ & $M$ & 78 & 22 & 6 & 6 & 3 & 3 & 2 & 1 \\
\hline G & $M$ & 76 & 12 & 6 & 6 & 1 & 1 & 0 & $\mathrm{~L}$ \\
\hline $\mathrm{H}$ & M & 67 & 11 & 4 & 6 & 3 & 1 & 1 & $\mathrm{~L}$ \\
\hline 1 & $M$ & 67 & 34 & 7 & 6 & 3 & 1 & 1 & $\mathrm{~L}$ \\
\hline 1 & $\mathrm{~F}$ & 73 & 8 & 1 & 6 & 0 & 1 & 0 & $\mathrm{~N}$ \\
\hline K & $M$ & 76 & 18 & 11 & 6 & 3 & 3 & 1 & 1 \\
\hline L & $M$ & 77 & 14 & 13 & 6 & 1 & 1 & 1 & $\mathrm{~L}$ \\
\hline
\end{tabular}

Dur. - duration, $M$ - male, $F$-female, $A \beta$ - amyloid- $\beta, P D$ - Parkinson disease, $D M$ - dementia, $N$ - not $A D, L$ - low level of $A D, I-$ intermediate level of $A D$ 
('A' score), neurofibrillary tangles (NFT) ('B' score), and neuritic plaques (NP) (' $C$ ' score), the distribution of the three scores equating to four levels of ADNC, viz. 'not', 'low', 'intermediate', and 'high'. The 12 PDD cases in the present study equated to levels of ADNC from 'not' to 'intermediate' levels of AD.

\section{Tissue preparation}

After death, the consent of next-of-kin was obtained for brain removal, following local Institutional Review Board procedures and the 1995 Declaration of Helsinki (as modified in Edinburgh, 2000). Brains were fixed in 10\% neutral buffered formalin for two weeks, paraffin-embedded, and sections cut at $6 \mathrm{~mm}$. Blocks were taken from frontal and temporal lobes, the latter including the amygdala, hippocampus $(H C)$, and dentate gyrus (DG). Histologic stains included hematoxylin and eosin and modified Bielschowsky silver impregnation. Immunohistochemistry was performed using the following antibodies: A $\beta$ (10D5, 1 : 100,000; Elan Pharmaceuticals, San Francisco, CA), phosphorylated tau (PHF-1, $1: 500$; supplied by Dr. Peter Davies, Albert Einstein Medical School, Bronx, NY), ubiquitin (Dako, Glostrup, Denmark) and phosphorylated $\alpha$-synuclein (1 : 10,000; Wako Chemicals USA Inc., Richmond, VA), and phosphorylated TDP-43 (pTDP-43, 1 : 40,000; Cosmo Bio Inc., Carlsbad, CA). Lewy bodies stage was assessed using a PD staging scale (range: 0, 1-6) $[15,16]$ and the McKeith et al. staging scale $[28,29]$.

\section{Morphological methods}

In the superior frontal gyrus (SFG) (BA 8,6), cingulate gyrus (CG) (BA 24), and entorhinal cortex (EC) (BA 28), the densities of $L B, L N$, and $L G$ were counted along strips of tissue orientated parallel to the pia mater, using $250 \times 50 \mu \mathrm{m}$ sample fields arranged contiguously [3]. The sample fields were located both in the upper and lower (laminae V/VI) cortex (minimum $n=32$ sample fields in each region), the short edge of the sample field orientated parallel with the pia mater and aligned with guidelines marked on the slide. In the HC, densities of inclusions were measured in sectors CA1 and CA2 ( $n=32$ fields in total), the short dimension of the sample field being aligned with the edge of the alveus. In the DG $(n=$ 32 fields), the sample fields were aligned to study the molecular and granule cell layers. In the amygdala ( $n=16$ fields), the fields were arranged across the maximum diameter of the basolateral nucleus, a region with severe $\alpha$-synuclein pathology in PDD [11]. All distinct $\alpha$-synuclein-immunoreactive rounded inclusions were counted as LB, LN were threadlike structures often contorted in shape, and small circular dot-like structures were identified as LG [11].

\section{Data analysis}

To determine patterns of clustering of the LB, LN, and $L G$, the data were analyzed by spatial pattern analysis [1-3] which was carried out on all brain regions with sufficient density of the pathology, i.e., at least 20 lesions were present along the strip of tissue analyzed. Departure from a random distribution can be measured by calculating the variance/ mean (V/M) ratio of the counts of a pathology in contiguous sample fields. If individuals of a pathology are randomly distributed, the number of samples containing $0,1,2,3 \ldots n$, inclusions should correspond to a Poisson distribution and the $\mathrm{V} / \mathrm{M}$ ratio should approximate to unity. A V/M ratio less than unity indicates a regular or uniform distribution of individual lesions and greater than unity a clumped or clustered distribution. If a pathology exhibits clustering along the strip of tissue examined, the mean size and distribution of the clusters can be estimated from counts in adjacent sample fields added together successively to provide data for increasing field sizes, e.g., $50 \times 250 \mu \mathrm{m}, 100 \times 250 \mu \mathrm{m}$, $200 \times 250 \mu \mathrm{m}$ etc., up to a size limited by the total length of strip sampled. The V/M ratio is plotted against field size. A V/M peak estimates the presence of regularly-spaced clusters and location of the peak indicates mean cluster size, statistical significance of a V/M peak being tested using the ' $\mathrm{t}$ ' distribution $[2,3]$. Mean cluster sizes of the LB, $L N$, and LG were compared among brain regions using a oneway analysis of variance (ANOVA). Relationships between spatial pattern, $\alpha$-synuclein pathology, and brain region were tested using chi-square $\left(\chi^{2}\right)$ contingency table tests. Correlations between cluster size of the $L B, L N$, and $L G$ and patient age, disease duration, and $A D N C$ ' $A B C$ ' stages were tested using Pearson's correlation coefficient (' $r$ '). As the number of analyses performed was large and without preplanned hypotheses, $p$ values were adjusted using the Bonferroni correction which suggested that a $p$ value of 0.001 should be used as the critical level to judge significance [5]. 


\section{Results}

Figure 1 shows the typical $\alpha$-synuclein-immunoreactive pathology in the EC of a case of PDD. Lewy bodies typically occur in small clusters whereas LN and LG are more widespread often developing in larger clusters.

Examples of the spatial pattern analysis are shown in Figure 2. In the upper laminae of the EC (Case A), LB exhibited a V/M peak at a field size of $100 \mathrm{~mm}$ suggesting a regular distribution of clusters of $L B, 100 \mathrm{~mm}$ in diameter, distributed parallel to the pia mater. In the lower laminae of the CG (Case A), $\mathrm{LN}$ exhibited a V/M peak at a field size of $400 \mathrm{~mm}$ suggesting a regular distribution of clusters $400 \mathrm{~mm}$ in diameter, distributed parallel to the pia mater. In the upper laminae of the CG (Case A), there was an increase in V/M of the LG with field size without reaching a peak, suggesting a large cluster of $L G$ of at least $800 \mathrm{~mm}$ in diameter.

The frequency of the different spatial patterns exhibited by the LB, LN, and LG in all regions and cases are summarized in Table II. In the majority of regions, the LB, LN, and LG were clustered and most frequently, the clusters were regularly distributed parallel to the tissue boundary. In addition, in a proportion of regions, the $L B, L N$, and $L G$ were randomly distributed or present in large, non-regularly distributed clusters

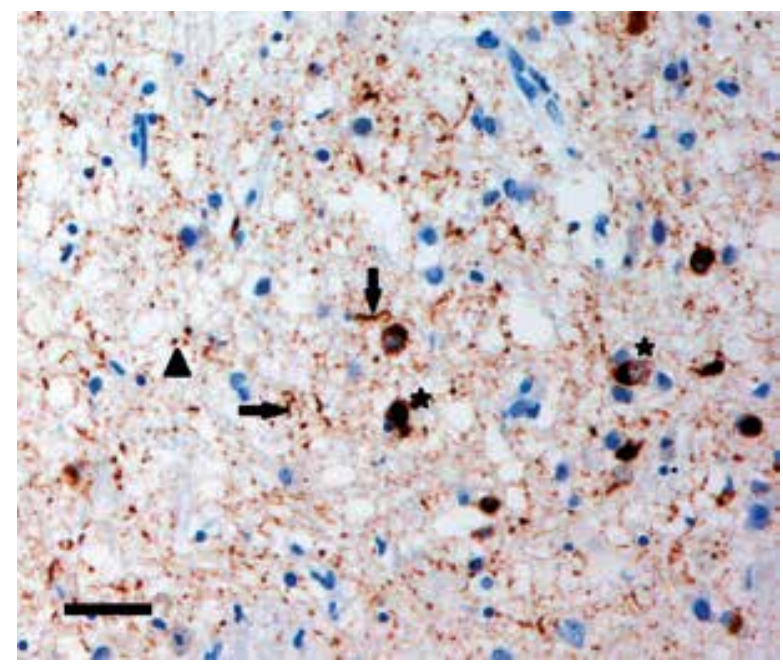

Fig. 1. The $\alpha$-synuclein pathology of a case of Parkinson disease dementia (PDD) showing Lewy bodies (LB) (star), Lewy neurites (LN) (arrow), and Lewy grains (LG) (arrowhead) in the entorhinal cortex ( $\alpha$-synuclein immunohistochemistry, hematoxylin, bar $=50 \mathrm{~mm}$ ).
$>800 \mathrm{~mm}$ in diameter. The LB and LN exhibited a similar range of spatial patterns $\left(\chi^{2}=6.11, p>0.05\right)$ but the LG were more frequently present in large, non-regularly distributed clusters than the LB $\left(\chi^{2}=21.04\right.$, $p<0.001)$ or the $\operatorname{LN}\left(\chi^{2}=9.51, p<0.05\right)$. No significant differences in the frequencies of spatial patterns were observed in upper compared with lower cortical laminae or in cortical regions compared with CA1/CA2, the dentate gyrus, and basolateral amygdala.

The frequency distribution of cluster sizes of the LB, LN, and LG in cortical regions, viz., SFG, CG, and $\mathrm{EC}$ is shown in Table III. The majority of clusters were in the size range of $100-800 \mathrm{~mm}$, significantly fewer gyri having cluster sizes as small as $50 \mathrm{~mm}$ or as large as $800 \mathrm{~mm}$. Mean cluster size of the LB, LN, and $\mathrm{LG}$ in each brain region is shown in Figure 3. ANOVA suggested that mean cluster size of the LB was significantly less than that of the LN and LG ( $F=7.19$, $p<0.001)$. There were no statistically significant differences in cluster size among regions.

Correlations among cluster size of the LB, LN, LG and patient age, disease duration, and NIA-AA ' $A B C$ ' stage are shown in Table IV. Several correlations were present but after Bonferroni adjustment only cluster size of the LN was positively correlated with NFT ('B') stage in the lower laminae of the EC $(r=0.99$, $p<0.001)$.

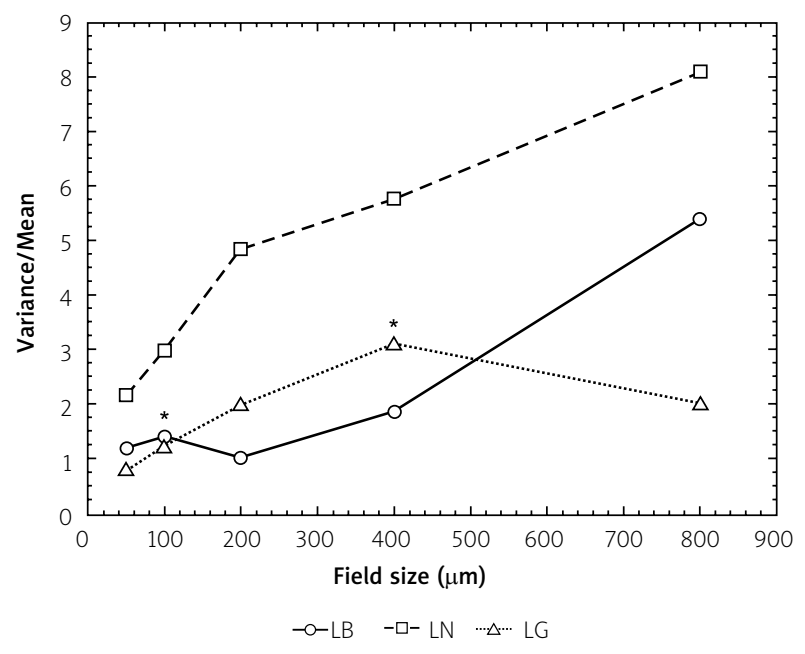

Fig. 2. Examples of the spatial patterns exhibited by Lewy bodies (LB), Lewy neurites (LN), and Lewy grains (LG) in a case of Parkinson disease dementia (PDD) (Case A). *Significant variance/ mean peaks. 
Table II. Frequency of different spatial patterns of the $\alpha$-synuclein pathology in twelve cases of Parkinson disease dementia (PDD)

\begin{tabular}{|c|c|c|c|c|c|c|}
\hline \multicolumn{7}{|c|}{ Frequency of spatial pattern } \\
\hline Region & Lesion & $N$ & $R$ & Reg & Regular clusters & Large clusters \\
\hline \multirow[t]{3}{*}{ SFG-U } & LB & 5 & 1 & 1 & 2 & 1 \\
\hline & LN & 8 & 0 & 3 & 3 & 2 \\
\hline & LG & 10 & 0 & 1 & 5 & 4 \\
\hline \multirow[t]{3}{*}{ SFG-L } & LB & 4 & 2 & 0 & 2 & 0 \\
\hline & LN & 9 & 0 & 2 & 3 & 4 \\
\hline & LG & 11 & 1 & 1 & 6 & 3 \\
\hline \multirow[t]{3}{*}{ CG-U } & LB & 6 & 3 & 0 & 3 & 0 \\
\hline & LN & 11 & 2 & 2 & 5 & 2 \\
\hline & LG & 12 & 2 & 3 & 4 & 3 \\
\hline \multirow[t]{3}{*}{ CG-L } & LB & 10 & 2 & 0 & 8 & 0 \\
\hline & LN & 12 & 2 & 0 & 8 & 2 \\
\hline & LG & 12 & 0 & 1 & 6 & 5 \\
\hline \multirow[t]{3}{*}{ EC-U } & LB & 9 & 1 & 0 & 7 & 1 \\
\hline & LN & 12 & 3 & 0 & 6 & 3 \\
\hline & LG & 11 & 1 & 0 & 5 & 5 \\
\hline \multirow[t]{3}{*}{$E C-L$} & LB & 7 & 0 & 1 & 6 & 0 \\
\hline & LN & 11 & 5 & 1 & 3 & 2 \\
\hline & LG & 11 & 0 & 1 & 7 & 3 \\
\hline \multirow[t]{3}{*}{ AM } & LB & 10 & 6 & 1 & 2 & 1 \\
\hline & LN & 10 & 2 & 1 & 6 & 1 \\
\hline & LG & 10 & 2 & 0 & 3 & 5 \\
\hline \multirow[t]{3}{*}{ CA1/2 } & LB & 7 & 1 & 0 & 5 & 1 \\
\hline & LN & 10 & 2 & 0 & 5 & 3 \\
\hline & LG & 12 & 0 & 3 & 6 & 3 \\
\hline \multirow[t]{3}{*}{$\mathrm{DG}(\mathrm{ML})$} & LB & 3 & 1 & 1 & 1 & 1 \\
\hline & LN & 1 & 0 & 0 & 1 & 0 \\
\hline & LG & 8 & 2 & 0 & 4 & 2 \\
\hline \multirow[t]{2}{*}{ DG (GCL) } & LN & 4 & 2 & 0 & 2 & 0 \\
\hline & LG & 8 & 0 & 0 & 6 & 2 \\
\hline
\end{tabular}

LB - Lewy bodies, LN - Lewy neurites, LG - Lewy grains, SFG - superior frontal gyrus, CG - cingulate gyrus, EC - entorhinal cortex, $U$ - upper cortex, $L$ - lower cortex, $A M$ - amygdala, CA1/2 - sectors of the hippocampus, $D G$ - dentate gyrus, $M L$ - molecular layer, GCL-granule cell layer, $N$ - number of regions studied, $R$-random distribution, $R e g$ - regular or uniform distribution of individual lesions

Statistical analysis: Comparison of frequencies (Chi-square $\left(\chi^{2}\right)$ contingency table tests totaled over regions): Comparison of different $\alpha$-synuclein pathologies $\chi^{2}=22.72(6 D F, p<0.001), L N$ vs. $L G \chi^{2}=9.51$ (3DF, $\left.p<0.05\right), L B$ vs. $L N \chi^{2}=6.11$ (3DF, $\left.p>0.05\right)$, LB vs. $L G \chi^{2}=21.04$ (3DF, $\left.p<0.001\right)$. Comparison of upper and lower cortex $L B \chi^{2}=3.69(3 D F, p>0.05), L N \chi^{2}=0.45(3 D F, p>0.05), L G \chi^{2}=3.29(3 D F, p>0.05)$. Comparison of cortical areas and HC/amygdala $L B \chi^{2}=3.57$ (3DF, $p>0.05), L N \chi^{2}=1.60(3 D F, p>0.05), L G \chi^{2}=1.89(3 D F, p>0.05)$.

\section{Discussion}

In cortical regions in PDD, the LB, LN, and LG were most frequently clustered and in a significant proportion of regions the clusters exhibited a regular distribution parallel to the pia mater. Similar clustering patterns were observed in sectors CA1/CA2 of the $\mathrm{HC}, \mathrm{DG}$, and basolateral amygdala. Hence, clustering of the $\alpha$-synuclein pathology in PDD is similar to that reported previously in various neurodegenerative dis- orders including the synucleinopathies DLB and MSA $[8,10]$. Clustering patterns of the $\alpha$-synuclein pathology in PDD are also similar to that of PrPsc deposits in CJD $[7,9]$ in which propagation of PrPsc among brain regions is particularly well documented $[12,13]$.

A number of features of the data suggest that $\alpha$-synuclein may have spread among brain regions via anatomical connections. First, in approximately $60 \%$ of cortical gyri, the LB, LN, and LG occurred in 
Table III. Frequency distribution of cluster size of $\alpha$-synuclein pathology ( $\%$ of totals in parentheses) in cortical regions of twelve cases of Parkinson disease dementia (PDD)

\begin{tabular}{|lccccc|}
\hline \multicolumn{7}{c|}{ Cluster size $(\mathrm{mm})$} \\
\hline Inclusion & $N$ & 50 & $100-200$ & $400-800$ & $>800$ \\
\hline Lewy bodies & 31 & $8(26)$ & $17(55)$ & $6(19)$ & 0 \\
\hline Lewy neurites & 43 & $8(19)$ & $15(35)$ & $13(30)$ & $7(16)$ \\
\hline Lewy grains & 48 & $9(19)$ & $15(31)$ & $16(33)$ & $8(17)$ \\
\hline
\end{tabular}

$N$ - number of brain regions studied

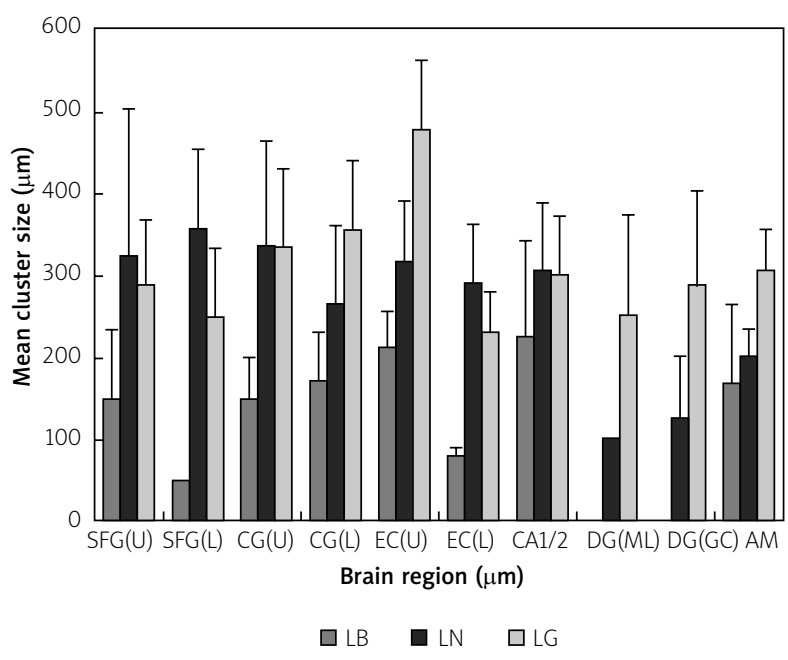

Fig. 3. Mean cluster sizes (bars $=\mathrm{SE}$ of mean) of the Lewy bodies (LB), Lewy neurites (LN), and Lewy grains (LG) in various brain regions (SFG - superior frontal cortex, CG - cingulate gyrus, EC - entorhinal cortex, CA1/2 - sectors of the hippocampus, DG - dentate gyrus, $\mathrm{ML}$ - molecular layer, GC - granule cell layer, AM - amygdala, $\mathrm{U}$ - upper cortex, $\mathrm{L}$ - lower cortex) in fifteen cases of Parkinson disease dementia (PDD). Analysis of variance (one-way ANOVA): among lesions $\mathrm{F}=7.19(p<0.001)$; among regions: $\mathrm{LB}$, $\mathrm{F}=0.70(p>0.05), \mathrm{LN}, \mathrm{F}=0.29(p>0.05), \mathrm{LG}$, $\mathrm{F}=1.12(p>0.05)$.

either small regularly distributed clusters 50-200 mm in diameter or in larger regularly distributed clusters $400-800 \mathrm{~mm}$ in diameter. The smaller clusters could reflect an association between the pathology and columns of cells originating either from the midbrain or brain stem nuclei which repeat at 30-40 mm intervals or the commissural and ipsilateral association fibers, which terminate in vertically oriented columns 200-500 mm in width [30]. The larger regularly distributed clusters $400-800 \mathrm{~mm}$ in diameter, however, are within the size range of the columns of cells associated with the cortico-cortical pathways $[19,22,32]$. These cells are themselves clustered and occur in bands regularly distributed along the cortex parallel to the pia mater $[19,22]$. Individual bands of cells have a mean dimension of approximately 500-1000 $\mathrm{mm}$ in width depending on the region, and traverse the laminae in columns; a similar size to the clusters of the $L B, L N$, and $L G$ is observed in $30 \%$ of gyri in PDD. Second, positive correlations between cluster size, disease duration, and NIA-AA ' $A$ ' or ' $B$ ' stage in some regions in a region over time or with developing ADNC co-pathology consistent with spread and recruitment of $\alpha$-synuclein. However, only the correlation between LN and NFT ' $B$ ' stage in the $\mathrm{EC}$ remained significant after Bonferroni adjustment suggesting less convincing evidence for an increasing burden of the pathology as the disease develops. Third, anatomically connected regions exhibited similar regularly distributed clusters, e.g. across the basolateral amygdala and in the CG and EC [17] and in dentate gyrus granule cells and EC ('perforant path') [6].

The data suggest a close relationship in PDD between the developing pathology and anatomical pathways which could have resulted from the spread of pathogenic $\alpha$-synuclein in PDD $[14,18,35]$. This raises the possibility, first proposed by Braak et al. [21], that a pathogenic agent introduced via ingestion or inhalation, may transfer along axons to basal areas of the brain, the brain stem, and then to the cerebral cortex. $\alpha$-Synuclein may be the target of this unknown agent causing protein misfolding and subsequent spread of $\alpha$-synuclein via connecting cells. Hence, olfactory deficits are an early non-motor feature of PD and the pathology could potentially spread via the olfactory bulb and vagal system to the substantia nigra [36]. Further spread into cortical and limbic areas could then occur with subsequent propagation of the pathology among cortical regions 
Table IV. Significant correlations (Pearson's ' $r$ ') between the cluster sizes of $\alpha$-synuclein pathology and patient age (years), duration of disease (years), and Alzheimer's disease stage of twelve cases of Parkinson disease dementia (PDD)

\begin{tabular}{|c|c|c|c|c|c|c|}
\hline \multicolumn{7}{|c|}{ Correlation } \\
\hline Region & Lesion & Age & $\begin{array}{c}\text { Duration } \\
\text { (PD) }\end{array}$ & $\begin{array}{c}\text { Duration } \\
\text { (Dem) }\end{array}$ & A-stage & B-stage \\
\hline SFG $(U)$ & LB & -0.06 & -0.18 & $-0.92^{\star}$ & 0 & 0.67 \\
\hline \multirow{2}{*}{ SFG (L) } & LN & $0.76^{\star}$ & 0.59 & -0.25 & 0.27 & $0.78^{*}$ \\
\hline & LG & 0.23 & $0.89^{*}$ & 0 & 0.33 & 0.31 \\
\hline CG (U) & LN & $0.58^{*}$ & -0.32 & -0.22 & 0.40 & 0.15 \\
\hline CG (L) & LN & 0.15 & 0.16 & -0.13 & $0.72^{\star \star}$ & 0.48 \\
\hline \multirow{2}{*}{$\mathrm{EC}(\mathrm{L})$} & LN & -0.69 & 0.16 & 0.50 & 0.44 & $0.97^{\star \star \star}$ \\
\hline & LG & $0.69^{*}$ & 0.27 & -0.10 & 0.26 & 0.55 \\
\hline \multirow{2}{*}{ CA1/2 } & LB & 0.47 & -0.23 & 0.46 & $0.70^{*}$ & 0.28 \\
\hline & LG & 0.27 & 0.01 & 0.35 & $0.74^{*}$ & -0.08 \\
\hline
\end{tabular}

LB - Lewy bodies, LN - Lewy neurites, LG - Lewy grains, SFG - superior frontal gyrus, CG - cingulate gyrus, EC - entorhinal cortex, CA1/2 - sectors of the hippocampus, $U$-upper cortical laminae, $L$ - lower cortical laminae

${ }^{*} p<0.05,{ }^{* *} p<0.01,{ }^{* *} p<0.001$. After Bonferroni adjustment only the correlation in bold remained significant.

via the cortico-cortical projections. Such a spread could therefore be an important factor in the development of dementia in PDD.

In conclusion, several features of the spatial patterns of the LB, LN, and LG suggest the anatomical spread of $\alpha$-synuclein pathology in PDD: (1) the pathology occurred in clusters which were regularly distributed parallel to the tissue boundary, (2) in several regions the estimated cluster size of the $L B, L N$, and LG was within the size range of cellular columns associated with the cortico-cortical pathways, (3) regularly distributed clusters were present in anatomically connected regions, and (4) the clustering pattern was similar to that of PrPsc deposits in CJD. If this hypothesis is correct, the presence of regularly distributed clusters of the pathology could be a useful indicator of this spread in both human patients and in animal models of the disease.

\section{Acknowledgements}

The 'Movement Disorders Center' at Washington University School of Medicine in St. Louis is gratefully thanked for providing the PDD cases for this study. In addition, Deborah Carter and Benjamin Vincent of the Betty Martz Laboratory for Neurodegenerative Research are thanked for their expert assistance.

\section{Disclosure}

Author reports no conflicts of interest.

\section{References}

1. Armstrong RA. The usefulness of spatial pattern analysis in understanding the pathogenesis of neurodegenerative disorders, with particular reference to plaque formation in Alzheimer's disease. Neurodegeneration 1993; 2: 73-80.

2. Armstrong RA. Analysis of spatial patterns in histological sections of brain tissue. J Neurosci Meth 1997; 73: 141-147.

3. Armstrong RA. Quantifying the pathology of neurodegenerative disorders: quantitative measurements, sampling strategies and data analysis. Histopathology 2003; 42: 521-529.

4. Armstrong RA. Methods of studying the planar distribution of objects in histological sections of brain tissue. J Microscopy 2006; 221: 153-158.

5. Armstrong RA. When to use the Bonferoni correction. Ophthal Physiol Opt 2014; 34: 502-508.

6. Armstrong RA, Cairns NJ, Lantos PL. Clustering of Pick bodies in the dentate gyrus in Pick's disease. Neuropathology 2000; 20: $170-175$

7. Armstrong RA, Lantos PL, Cairns NJ. The spatial pattern of prion protein deposits in patients with sporadic Creutzfeldt-Jacob disease. Neuropathology 2001; 21: 19-24.

8. Armstrong RA, Lantos PL, Cairns NJ. What does the study of spatial patterns of pathological lesions tell us about the pathogenesis of neurodegenerative disease? Neuropathology 2001; 21: 1-12.

9. Armstrong RA, Cairns NJ, Ironside JW, Lantos PL. The spatial patterns of prion protein deposits in cases of variant Creutzfeldt-Jakob disease. Acta Neuropathol 2002; 104: 665-669.

10. Armstrong RA, Cairns NJ. Different molecular pathologies result in similar spatial patterns of cellular inclusions in neurodegenerative disease: a comparative study of eight disorders. J Neural Transm 2012; 119: 1551-1560.

11. Armstrong RA, Kotzbauer PT, Perlmutter JS, Campbell MC, Hurth KM, Schmidt RE, Cairns NJ. A quantitative study of $\alpha$-synu- 
clein pathology in fifteen cases of dementia associated with Parkinson disease. J Neural Transm 2014; 121: 171-181.

12. Beekes M, McBride, PA, Baldauf E. Cerebral targeting indicates vagal spread of infection in hamsters fed with scrapie. J Gen Virol 1998; 79: 601-607.

13. Beekes M, McBride PA. Early accumulation of pathological prion protein in the enteric nervous system and gut-associated lymphoid tissue of hamsters orally infected with scrapie. Neurosci Lett 2000; 278: 181-184.

14. Beekes M, Thomzig A, Schultz-Schaeffer W, Burger R. Is there a risk of prion-like transmission by Alzheimer- or Parkinson-associated protein particles. Acta Neuropathol 2014; 128: 463-476.

15. Braak H, del Tredici K, Rub U, de Vos RAI, Steur ENHJ, Braak E. Staging of brain pathology related to sporadic Parkinson's disease. Neurobiol Aging 2003; 24: 197-211.

16. Braak H, Ghebremedhin E, Rub U, Bratzke H, Del Tredici K. Stages in the development of Parkinson disease-related pathology. Cell Tissue Res 2004; 318: 121-134

17. Brodal A. Neurological anatomy. $3^{\text {rd }}$ ed. Oxford University Press, New York and Oxford, 1981.

18. Cooper JM, Wiklander PBO, Nordin JZ, Al-Shawi R, Wood MJ, Vithiani M, Scapira AHV, Simons JP, El-Andaloussi S, AlvarezErviti L. Systemic exosomal siRNA delivery reduced alpha-synuclein aggregates in brains of transgenic mice. Mov Disord 2014; 29: 1476-1485.

19. De Lacoste M, White CL. The role of cortical connectivity in Alzheimer's disease pathogenesis: a review and model system. Neurobiol Aging 1993; 14: 1-16.

20. Emre M, Aarsland D, Brown R, Burn DJ, Duyckaerts C, Mizuno Y, Broe GA, Cummings J, Dickson DW, Gauthier S, Goldman J, Goetz C, Korczyn A, Lees A, Levy R, Litvan I, McKeith I, Olanow W, Poewe W, Quinn N, Sampaio C, Tolosa E, Dubois B. Clinical diagnostic criteria for dementia associated with Parkinson's disease. Mov Disord 2007; 15: 1680-1707.

21. Hawkes CH, Del Tredici K, Braak H. Parkinson disease: a dua hit hypothesis. Neuropathol Appl Neurobiol 2007; 33: 599-614.

22. Hiorns RW, Neal JW, Pearson RCA, Powell TPS. Clustering of ipsilateral cortico-cortical projection neurons to area 7 in the rhesus monkey. Proc Roy Soc (Lond) 1991; 246: 1-9.

23. Holmes BB, Devos SL, Kfoury N, Li M, Jacks R, Yanamandra K, Ouidja MO, Brodsky FM, Marasa J, Bagchi DP, Kotzbauer PT, Miller TM, Papy-Garcia D, Diamond MI. Heparan sulfate proteoglycans mediate internalization and propagation of specific proteopathic seeds. Proc Natl Acad Sci USA 2013; 110: E3138-E3147.

24. Hughes AJ, Daniel SE, Kilford L, Lees AJ. Accuracy of clinical diagnosis of idiopathic Parkinson disease: a clinic-pathological study of 100 cases. J Neurol Neurosurg Pyschiatr 1992; 55: 181-184.

25. Hyman BT, Phelps CH, Beach TG, Bigio EH, Cairns NJ, Carrillo MC, Dickson DW, Duyckaerts C, Frosch MP, Masliah E, Mirra SS, Nelson PT, Schneider JA, Thal DR, Thies B, Trojanowski JQ, Vinters HV, Montine TJ. National Institute on Aging-Alzheimer's Association guidelines for the neuropathologic assessment of Alzheimer's disease. Alz \& Dement 2012; 8, 1-13.

26. Kotzbauer PT, Cairns NJ, Campbell MC, Racette BA, Tabbal SD, Perlmutter JS. Pathological accumulation of $\alpha$-synuclein and $A \beta$ in Parkinson disease patients with dementia. Arch Neurol 2012; 23: 1-6.
27. Kovacs GG, Milenkovic IJ, Preusser M, Budka H. Nigral burden of alpha-synuclein correlates with striatal dopamine deficit. Mov Disord 2008; 23: 1608-1612.

28. McKeith IG, Galasko D, Kosaka K, Perry EK, Dickson DW, Hansen LA, Salmon DP, Lowe J, Mirra SS, Byrne EJ, Lennox G, Quinn NP, Edwardson JA, Ince PG, Bergeron C, Burns A, Miller BL, Lovestone S, Collerton D, Jansen ENH, Ballard C, de Vos RAI, Wilcock GK, Jellinger KA, Perry RH. Consensus guidelines for the clinical and pathologic diagnosis of dementia with Lewy bodies (DLB): report of the consortium on DLB international workshop. Neurology 1996; 47: 1113-1124

29. McKeith IG, Dickson DW, Lowe J, Emre M, O’Brien JT, Feldman H, Cummings J, Duda JE, Lippa C, Perry EK, Aarsland D, Arai H, Ballard CG, Boeve B, Burn DJ, Costa D, Del Ser T, Dubois B, Galasko D, Gauthier S, Goetz CG,Gomez-Tortusa E, Holliday G, Hansen LA, hardy J, Iwatsubo T, Kalaria RN, Kaufer D, Kenny RA, Korczun A, Kosaka K, Lee VMY, Lees A, Litvan I, Londos E, Lopez OL, Minoshima S, Mijano Y, Molina JA, Mukaetova-Landinska EB, Pasquier F, Perry RH, Schultz JB, Trojanowski JQ, Yamada M. Diagnosis and management of dementia with Lewy bodies: third report of the DLB Consortium. Neurology 2005; 65: 18631872.

30. Mountcastle VB. An organizing principle for cerebral function: The unit module and the distributed system. In: The Neurosciences. $4^{\text {th }}$ Study Program. Schmitt FO, Worden FG (eds.). 1979; 21-42.

31. Papp MI, Lantos PL. The distribution of oligodendroglial inclusions in multiple system atrophy and its relevance to clinical symptomology. Brain 1994; 117: 235-243.

32. Pearson RCA, Esiri MM, Hiorns RW, Wilcock GK, Powell TPS. Anatomical correlates of the distribution of the pathological changes in the neocortex in Alzheimer's disease. Proc Natl Acad Sci 1985; 82: 4531-4534.

33. Saito Y, Ruberu NN, Sawabe M, Arai T, Tanaka N, Kakuta Y, Yamanouchi H, Marayama S. Staging of argyrophilic grains: an age-associated tauopathy. J Neuropathol Exp Neurol 2004; 63: 911-918.

34. Spillantini MG, Crowther RA, Jakes R, Cairns NJ, Lantos PL, Goedert M. Filamentous alpha-synuclein inclusions link multiple system atrophy with Parkinson disease and dementia with Lewy bodies. Neurosci Lett 1998; 251: 205-208.

35. Steiner JA, Angot E, Brunden P. A deadly spread: cellular mechanisms of $\alpha$-synuclein transfer. Cell Death and Differentiation 2011; 18:1425-1433.

36. Ubeda-Bannon I, Saiz-Sanchez D, De la Rosa-Prieto, MartinezMarcos A. Alpha-synuclein in the olfactory system in Parkinson's disease: role of neural connections on spreading pathology. Brain Struc Funct 2014; 219: 1513-1526.

37. Voipicelli-Daley LA, Luk KC, Patel TP, Tanik SA, Eiddle DM, Stieber A, Meaney DF, Trojanowski JQ, Lee VMY. Exogenous alphasynuclein fibrils induce Lewy body pathology leading to synaptic dysfunction and neuron death. Neuron 2011; 72: 57-71. 